\title{
MAREA UNIRE DIN 1918 ŞI BISERICA
}

\author{
Pr. Prof. Dr. Cezar Vasiliu
}

Univ. Sherbrooke Canada

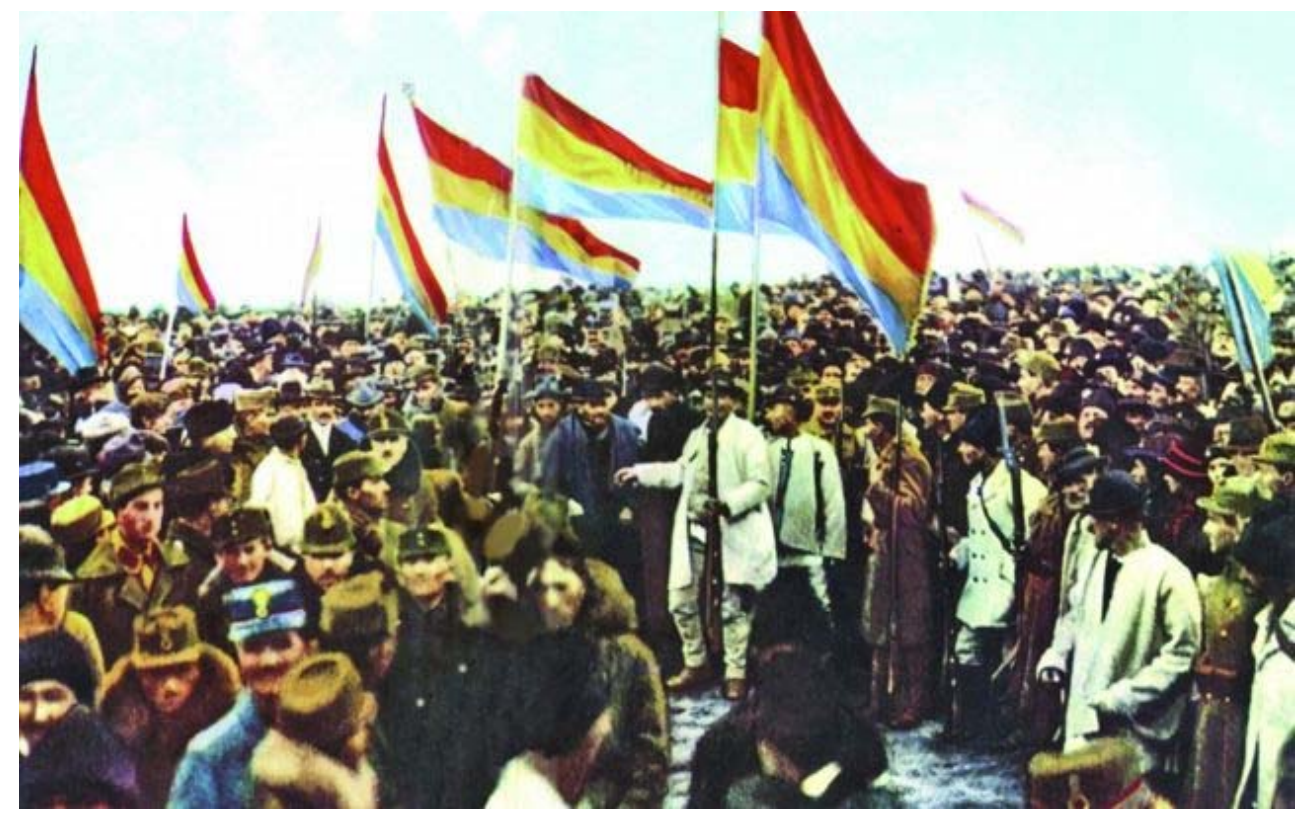

La 1 Decembrie 2018, românii de pretutindeni, din ţară şi din afara graniţelor geografice, sărbătoresc 100 de ani de la Marea Unire de la Alba Iulia, când, sub conducerea înţeleaptă a Regelui Ferdinand Întregitorul s-a realizat România Mare. Pentru noi, românii, anul 1918 a fost un an providenţial. La 27 Martie 1918 Basarabia lacrima neamului românesc - revenea la Patria Mamă; la 28 Noiembrie 1918 era rândul Bucovinei - cu obcinele şi mânăstirile sale -, pentru ca la 1 Decembrie 1918, la Alba Iulia devenită capitală de suflet a neamului românesc - să se realizeze unul din visele seculare ale naţiunii române, desăvârşirea statului naţional unitar, prin Unirea Transilvaniei, Banatului, Crişanei şi Maramureşului cu România.

Alba Iulia, mândrul oraş transilvan, mai fusese martora unor evenimente de seamă ale istoriei şi culturii române. Aici, realizase Mihai Viteazul, la 21 Octombrie 1599, prima Unire politică a celor trei Ţări Româneşti; tot aici a apărut, la 20 Ianuarie 1648, "Noul Testament de la Bălgrad" al mitropolitului Simion Ştefan. La Alba Iulia au suferit martiriul, la 28 Februarie 1785, Horia şi Closca şi tot aici, vor fi încoronaţi, la 15 Octombrie 1922, Regele Ferdinand şi Regina Maria, ca primii suverani ai României Mari.

$\mathrm{Pe}$ fundalul succesiunii evenimentelor istorice din anul 1918 vom încerca, în cele ce urmează, să subliniem contribuţia Bisericii Româneşti, Ortodoxă şi Greco-Catolică, la Marea Unire. România intrase în primul Război mondial pentru "împlinirea dezideratului fundamental al desăvârşirii statutului naţional" - cum preciza C. C. Giurăscu. În toamna anului 1918, Monarhia austro-ungară se destramă ca stat, datorită crizei celor patru ani de război, înrăutăţirii situaţiei economice şi, mai ales, a ridicării naţiunii din dubla monarhie, între care şi românii din Transilvania. La 12 Octombrie 1918, după manifes-tările de la Cluj, Brasov, Arad, Reşiţa şi Petroşani, Comitetul executiv al Partidului Naţional 
Român din Transilvania a formulat o declaraţie prin care proclamă dreptul inalienabil la viaţă liberă a românilor din dubla monarhie. Declaraţia a fost citită în Parlamentul de la Budapesta, la 18 Octombrie al aceluiaşi an, de către deputatul Alexandru Vaida-Voievod (greco-catolic), ultima la care au participat delegaţii ardeleni.

Intre Octombrie-Noiembrie 1918 au luat fiinţă în Transilvania şi Banat, Consiliile naţionale româneşti, iar la 30 Octombrie 1918 s-a constituit la Arad, Consiliul Naţio-nal Român, ca "unic for care reprezintă voinţa poporului român". Sub conducerea sa s-a intensificat lupta pentru reunificarea cu Țara. Slujitorii Bisericii Româneşti - Ortodoxe şi Greco-Catolice - s-au aflat în primele rânduri ale luptătorilor pentru unitate naţională, deziderat pentru care militau şi periodicele religioase din Ardeal.

$\mathrm{Ca}$ exemplu al fraternităţii Ierarhilor români din Transilvania - ortodocşi şi grecocatolici - care ar putea servi de pildă şi pentru situaţia de astăzi, menţionăm şi faptul că, la 21 Noiembrie 1918, cei cinci Episcopi români, ortodocşii Ioan Papp al Aradului şi Miron Cristea al Caransebeşului şi grecocatolicii Iuliu Hossu al Gherlei (devenit apoi cardinal), Dimitrie Radu al Oradei şi Valeriu Traian Frentiu al Lugojului, au semnat o "Declaraţie de adeziune" la C.N.R., prin care1 recunoşteau "ca singurul conducător politic al naţiunii române". Actul a avut un ecou pozitiv în rândul clerului şi credincioşilor celor două Biserici surori.

La 14 Noiembrie 1918, profesorul Nicolae Bălan şi căpitanul Victor Precup erau trimişi de C.N.R. la Iaşi pentru a discuta cu conducătorii de atunci ai ţării situaţia din Transilvania. La 15 Noiembrie 1918, la propunerea prof. Bălan, C.N.R. hotăra convocarea unei Mari Adunări Naţionale, cu deputaţii aleşi şi reprezentanţi ai tuturor organizaţiilor româneşti.

Duminică 1 Decembrie 1918, a avut loc la Alba Iulia, Adunarea Naţională care a decis unirea cu România. Erau prezenţi 1228 deputaţi şi delegaţi oficiali, alături de 100 de mii de români veniţi din toate părţile unde se vorbea româneşte, de la Maramureş la Dunărea bănăţeană, din Ţara Bârsei până-n cea a Crişurilor. Între ei se aflau şi reprezentanţii Bisericii. S-a început prin slujbe urmate de Te Deum-uri în bisericile ortodoxă şi greco-catolică din Alba Iulia, după care delegaţii s-au reunit în sala Cercului Militar, sub preşedenţia lui Cicio-Pop. În biroul adunării au fost aleşi trei președinţi George Pop din Băseşti, episcopul Dimitrie Radu al Oradei (unit) şi episcopul Ioan Papp (ortodox).

Raportul principal a fost prezentat de Vasile Goldis (ortodox) care a citit şi proiectul rezoluţiei, devenit Hotărîrea de unire a Transilvaniei cu România care începea astfel: "Adunarea naţională a tuturor românilor din Transilvania, Banat şi Ţara Ungurească, adunaţi prin reprezentanţii lor indreptătiţi la Alba Iulia în ziua de 1 Decembrie 1918, decretează Unirea acestor români și a teritoriilor locuite de dânșii $\mathrm{cu}$ România. Adunarea națională proclamă indeosebi dreptul inalienabil al naţiunii române la întreg Banatul, cuprins între râurile Mureş, Tisa şi Dunăre". Goldis și-a încheiat raportul cu cuvintele "legătura sfântă a celor 14 milioane de români ne îndreptăţeşte azi să zicem Trăiască România Mare!".

Ultimul orator a fost Iuliu Maniu, grecocatolic, care a vorbit în numele Partidului Naţional Român din Transilvania - discurs prohibit peste patru decenii în România. Iată un scurt fragment: "... Dacă privim inapoi la suferintele îndurate de neamul românesc, dacă ne amintim de sângele vărsat, nu ştiu cum să multumim lui Dumnezeu, că ne-a dat nouă, celor din generaţia de acum, să trăim aceste timpuri de înălţare... Inainte de a lua hotărîri trebuie să ne închinăm înaintea acelora care au ajutat ca lumina libertăţii neamurilor să străbată norii. Aceștia sunt vitejii din glorioasa armată română, conduşi de marele căpitan, Regele Ferdinand (...) Unirea tuturor românilor într-un singur Regat şi într-un nedespărtit stat este nu numai un ideal sfânt, ci şi un drept inalienabil al nostru în baza fiinţei noastre naţionale unitare. (...) Noi, românii din Transilvania, Banat şi Ungaria suntem in drept şi avem datoria să pretindem această Unire, pentru că aici a fost leagănul românismului (...) (St. Neagoe, Istoria Unirii Românilor, ed. Diogene, Bucureşti, 1993, p. 287-290).

La ora 14, delegaţii au mers pe Câmpul lui 
Horia unde aşteptau cei peste o sută de mii de români. S-au rostit mai multe discursuri. Episcopul Miron Cristea al Caransebesului a spus, între altele: "Nu ne putem gândi astăzi la altceva decât la aceea ce au hotărît şi au făcut fraţii din Basarabia şi Bucovina, adică la Unirea cu scumpa noastră România, alipindu-i întreg pământul strămoşesc". După care a poftit pe episcopul Iuliu Hossu al Gherlei să citească Hotărîrea Unirii, urmată de cuvintele: "Fericit am vestit hotărîrea judecăţii lui Dumnezeu prin reprezentanţii a toată suflarea românească; fericiţi voi, care aţi pecetluit pe veci Unirea cu Ţara Mamă. O viaţă întreagă veţi mărturisi cu mândrie «Şi eu am fost la Alba Iulia». Trăiască România Mare, una şi în veci nedespărţită".

Entuziasmul mulţimii ajunsese la culme. Glasuri, vibrând de mândrie naţională, scandau "Suntem uniţi cu Ţara" sau "Trăiască România Mare". Cei doi episcopi, Cristea şi Hossu se îmbrăţişau fericiţi, cu roua bucuriei în priviri, iar episcopul Cristea profeţea: "Pe cum ne vedeţi aici îmbrăţişaţi frăţeşte, aşa să rămână îmbrăţişaţi, pe veci, toţi fraţii României" (idem, p. 292).

Adunarea a ales Marele Sfat Naţional - 212 membri - în care au intrat cei cinci episcopi români, teologi, protoierei şi preoţi. La 2 Decembrie, Marele Sfat Naţional a ales Consiliul dirigent, iar la 14 Decembrie o delegaţie alcătuită din Vasile Goldis, Alexandru Vaida Voievod şi episcopii Cristea şi Hossu au prezentat la Bucureşti Regelui Ferdinand actul Unirii Transilvaniei cu România. Atestarea hotărîrii istorice de la 1 Decembrie 1918 a fost făcută prin decretul regal din 11 Decembrie 1918, investit cu putere de votul Parlamentului din 29 Ianuarie 1919.

În acelaşi timp în Banat situaţia generală era mai confuză datorită ocupaţiei militare. La începutul lui 1919 s-a constituit "Liga Bănăţeană", condusă de diaconul Avram Imbroane (ortodox) cu scopul de a informa opinia publică şi Conferinţa de pace de la Paris despre drepturile românilor din acest teritoriu.

La 8 Ianuarie 1919, Consiliul naţional săsesc din Medias a aprobat hotărîrea de la Alba Iulia, decizie asemănătoare luând şi şvabii din Banat, reuniţi la Timişoara la 10 August 1919, O delegaţie a "Ligii bănăţene" a mers la Paris prezentând un memoriu asupra drepturilor noastre asupra acestui teritoriu. Unirea Transilvaniei cu Țara a adus schimbări radicale şi în viaţa Bisericii, mai ales a celei ortodoxe. Ierarhii din provinciile alipite au intrat, la 30 Decembrie 1919, în componenţa Sfântului Sinod de la Bucureşti, conform rânduielilor canonului 34 apostolic. La 31 Decembrie 1919, episcopul Miron Cristea devenea Mitropolitul Primat al României. Au fost reînfiinţate episcopiile Oradei (1920), Clujului şi Armatei (1921), Tomisului, Cetăţii Albe şi Hotinului (1923). Mai mult, ardelenii au fost privilegiaţi în alegerile de episcopi. Alături de Miron Cristea, au devenit episcopi: Lazăr Duma la Argeş, Lucian Triteanu la Roman, Justinian Teculescu la Ismail, protopopul de Sălişte, Ioan Stoica, la Armată şi cel de Braşov, Vasile Saftu, la Râmnic. La Sibiu a devenit mitropolit prof. Nicolae Bălan, iar la Cluj episcop Nicolae Ivan. Catedra de Istoria românilor de la noua Universitate clujeană va fi ocupată de protoiereul de Sălişte, prof. Ioan Lupaş.

Una din marile împliniri ale Unirii de la 1 Decembrie 1918 a fost construirea catedralei ortodoxe din Alba Iulia, în numai un an şi jumătate, având ca arhitect pe V. G. Ştefănescu şi pictor pe Costin Petrescu. Ea a fost sfinţită la 15 Octombrie 1922 de către Mitropolitul-Primat Miron Cristea, cu ocazia încoronării Regelui Ferdinand şi a Reginei Maria. La 4 Februarie 1925, Sfântul Sinod al Bisericii Ortodoxe Române aproba ridicarea Bisericii noastre la rang de Patriarhie, confirmată prin "Tomos"-ul Patriarhului Ecumenic, din 30 Iunie 1925. Înscăunarea primului Patriarh al României - Miron Cristea - a avut loc la Bucureşti, la 1 Nov. 1925.

Legea şi Statutul de organizare a Bisericii Ortodoxe Române, prevăzând participarea masivă a laicilor la viaţa Bisericii conform Statutului şagunian, consfinţea astfel autocefalia Bisericii - obţinută în 1885, în urma independenţei de stat dobândită prin luptă în 1877 -. Ele prevedeau existenţa a cinci mitropolii - Ungro-Vlahia, Moldova şi Transilvania, plus a Mitropoliei Bucovinei, cu Arhiepiscopia Cernăuţilor şi Episcopia Hotinului, şi a Mitropoliei Basarabiei, înfiinţată în 1927, cu Arhiepiscopia Chişinăului şi Episcopia Cetăţii Albe. 
În 1920, Guvernul român a intrat în tratative diplomatice cu Vaticanul, iar în 1921 s-a deschis Legaţia română pe lângă Vatican şi Nuntiatura apostolică la Bucureşti. La 10 Mai 1927, la stăruinţa Regelui Ferdinand I (catolic) s-a semnat Concordatul cu Vaticanul. Ritul latin avea o mitropolie la Bucureşti, cu 4 episcopii sufragane şi alta la Iaşi. Ritul greco-catolic avea Mitropolia Blajului, cu 4 episcopii sufragane. În 1928 sa emis o nouă Lege a Cultelor care a fost valabilă până în 1948, an în care Biserica soră greco-catolică a fost desfiinţată prin lege. Restabilirea ei juridică s-a făcut după evenimentele din Decembrie 1989.

Constatăm că până în anul 1918 a existat o frumoasă colaborare între Ierarhii, preoţii şi credincioşii celor două Biserici naţionale românești - ortodoxă şi greco-catolică. Ei au fost împreună în momentele de răscruce din viaţa poporului român: răscoala lui Horia, Cloşca şi Crişan; Supplex-ul; Memoriile lui V. Moga şi I. Lemeni; revoluţia din 1848; ASTRA; Memorandumul sau primul Război mondial (Pr. prof. M. Păcurariu).

Desfiinţarea Bisericii greco-catolice în 1948 a însemnat bunuri confiscate, episcopi şi preoţi arestaţi. Şase epoiscopi greco-catolici vor muri în temnită în urma tratamentelor fizice şi morale inumane: Vasile Aftenie al Bucureştiului (+1950); Ioan Suciu al Blajului $(+1953)$; Traian Frenţiu al Oradei $(+1952)$; Titus Livius Chinezu al Bucureştilor (+1955); Ioan Bălan al Lugojului (+1960); Alexandru Rusu al Băii Mari (+1963); alţii vor suferii ca Iuliu Hossu al Gherlei-Clujului (+1970) - în ultima parte a vieţii cu domiciliul forțat la mânăstirea Căldăruşani şi Iuliu Hirte (+1978). Alături de ei au murit şi 4 episcopi catolici de rit latin, Alexandru Cisar al Bucureştiului $(+1950)$, Antonie Durcovici al Iaşilor $(+1950)$, Francis Staffler al Oradei (+1957) şi Augustin Pasa al Timisoarei $(+1955)$.

Desigur şi Biserica Ortodoxă Română îşi are martirii săi. Tot în perioada comunistă au pierit numeroşi mireni şi preoţi ortodocşi la Canal sau în temnitele de tristă amintire. Martirologiul Neamului Românesc cuprinde pe Patriarhul Nicodim Munteanu (+1948), pe Mitropoliţii Irineu Mihălcescu al Moldovei $(+1948)$, Tit Simedrea al Bucovinei (retras în 1945, + 1971), Efrem Enăcescu al Basarabiei (alungat în 1944, + 1968) şi pe episcopii Nicolae Popovici al Oradei (pensionat forţat în 1950, +1960) sau Grigore Leu al Huşilor (+1949). Pe toţi aceştia, precum şi pe preoţii şi credincioşii martirizaţi de comunişti, Biserica Ortodoxă Română are datoria morală să-i canonizeze într-o zi pe care ne-o dorim cât mai apropiată.

Consider, deci, că cea mai potrivită încheiere o constituie cuvintele Regelui Ferdinand I rostite la încoronare la Alba Iulia, la 15 Octombrie 1922: "Mă închin cu evlavie memoriei celor care, in toate vremurile şi pretutindeni, prin credinţa lor, prin munca şi prin jertfa lor au asigurat unitatea naţională şi salut cu dragoste pe cei care au proclamato, într-un glas şi o simţire, de la Tisa până la Nistru şi până la Mare" Ferdinand I - Regele tuturor românilor.

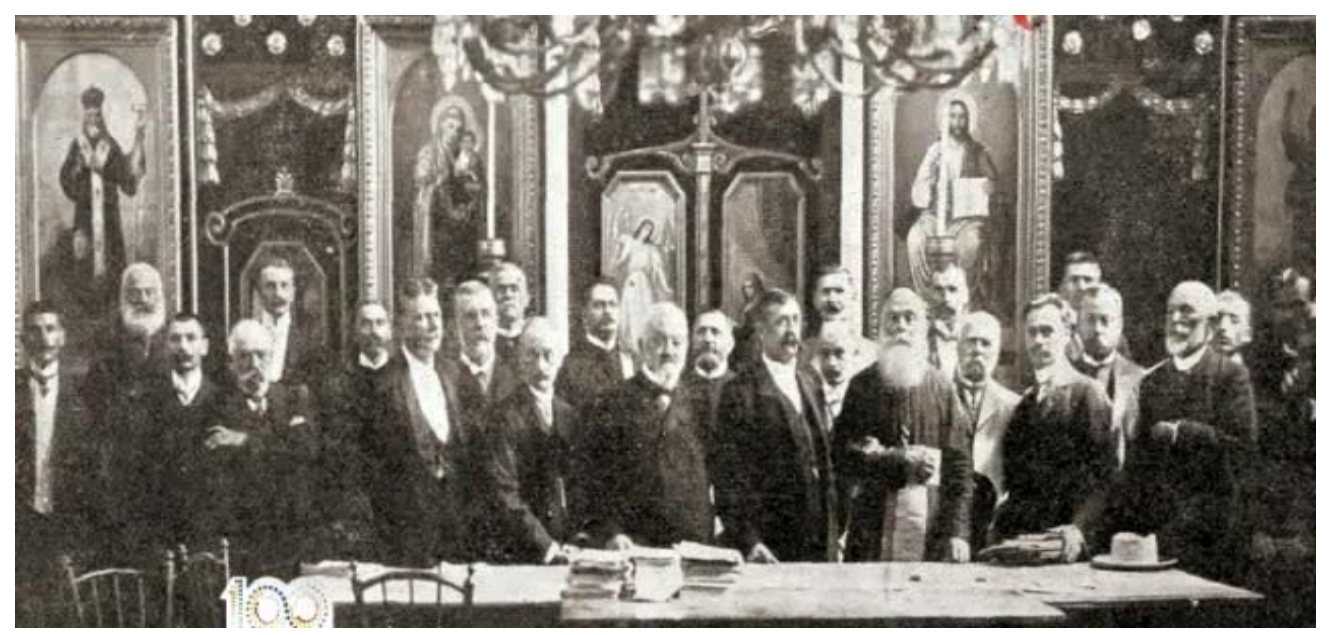

